\title{
FORMATIVE ASSESSMENT IN HIGHER EDUCATION INSTITUTIONS
}

\author{
Ianina Gigiberia, Professor, Doctor of Engineering in Informatics, Georgian National University \\ (SEU), Georgia, Tbilisi \\ Maia Kevkhishvili, Professor, Doctor of Engineering in Informatics, Georgian Technical University, \\ Georgia, Tbilisi
}

DOI: https://doi.org/10.31435/rsglobal_conf/25112020/7250

\begin{abstract}
The article reviews the use of formative assessment in institutions of higher education. It is crucial for making most out of the students' potential. Formative assessment helps increase student motivation and corrects misconceptions. Creating a differentiated learning environment when specific learning needs are identified enable us to build new knowledge and experience based on the right perceptions.
\end{abstract}

Keywords: formative assessment, feedback, differantiated teaching, teaching software.

Introduction. The educational process carried out in higher education institutions as per the requirements of the twenty-first century ensures the competitiveness of the graduates and their subsequent invaluable contribution to the development of the country.

Necessary condition of the teaching-learning modern requirements is for the student to be at the center of the learning process, his development process and the result achieved by him. Being outcome-oriented means transforming the knowledge acquired by the student into functional knowledge and, consequently, its active use in various directions.

The quality of learning outcomes is determined through assessment. When a point is written in a student's assessment, a formal assessment of the level achieved is made. In order to control the dynamics of student development, it is necessary to pay special attention to formative assessment - at this time the learning process is evaluated, which contributes to the improvement of the quality of learning, its development.

Research results. Studying in institutions of higher education - a wide range of formative assessment techniques are used to measure the effectiveness and efficiency of teaching. There's a partial overlap among the subtypes of formative assessment.

In formative assessment we can use:

- Verbal comment;

- Counseling;

- Self-assessment and peer assessment scheme, etc.

For the development of the student's learning and teaching process, at all seminars, or practice, during each activity the sudent should be monitored and assessed, which will not be reflected in points, but aimed at improving the student's learning quality, full realisation of his/her potential - it will be formative assessment.

Such an assessment allows us to study the student in many ways. In particular, it should reveal what is difficult, whether there is progress, what is the reason for failure, the individual characteristics of students, their strengths and weaknesses. In the teaching process, it is important for the lecturer to provide feedback on what works well for the student, what can be done better, and how the student can improve the outcome.

The ongoing assessment provides comprehensive, exhaustive information about the student. Mor over, the ongoing assessment gives the lecturer the opportunity to reflect on his / her own daily activities. Based on how well he achieved the goal (s)he set, (s)he can analyse what worked, what (s)he would change for a better result, and so on.

Formative assessment strategies may be presented in a question-and-answer format. The lecturer asks students questions and analyses the answers. This can be the specific tasks of the observations made during the discussions, the analysis of the project results, and so on. Based on the data obtained, it is possible to use highly tailored teaching strategies and improve the student learning process.

Based on the available research, we can conclude that the more students participate in setting the goals, the better they understand both the goals and the criteria for achieving those goals. They 
should be involved in determining and describing what a good, exemplary work should look like, what criteria should be used to define achievement/non-achievement of goals, and what procedures are needed in the process of moving toward those goals.

Formative assessment is successful when the purpose, content and teaching of the course are fully related, as well as the assessment procedures and results. Therefore, the lecturer of the higher education institution should develop such feedback that will link the assessment results to teaching and learning.

Student involvement is a key component of the formative assessment process. The student should be able to self-assess, outline ways to monitor their own learning process, and therefore use the results obtained to modify the learning process.

Formative assessment will timely identify students' misconceptions and misdirection in the learning process, which to correct requires timely work and the use of differentiated teaching methods. The kind of differentiation that the teacher should make is provided by the diagnostic assessment, which is a sub-component of the developmental assessment. Its purpose is to find / discuss the reasons for students' success / failure and use the results obtained to fully realise their potential.

An interim assessment, conducted once or twice a semester, determines a student's success at a particular stage of teaching and learning. The purpose of the mid-term assessment tools is to measure the result achieved by the student through testing or any other form of summary procedure, comparing it with the results provided in the syllabus. Points are earned at this time, which indicates the student's success in the relevant field. However, interim evaluation does not allow diagnosing a problem identified in the teaching-learning process.

Differentiation can be done according to process and product. Differentiation by process means choosing which strategies to use to maximise student potential (e.g., some prefer reading information found on the Internet, some prefer listening, some prefer mutual learning, etc.). Differentiation by product means that the student chooses how he or she wants to demonstrate his or her knowledge (e.g., some prefer to present alternative solutions to the problem in the form of an essay, some in the form of a presentation, some prefer building a specific model, etc.).

The differentiated learning process in a higher education institution, as well as in any general education institution, is based on readiness, interests and learning style. Differentiation should be applied according to any of these factors or any combination of them. Successful differentiated teaching requires constant monitoring and evaluation of the teaching-learning process. During differentiated teaching the lecturer should observe and evaluate:

- Is the student progressing?

- How solid is their knowledge and understanding?

- Do any students or groups of students need extra work on a particular issue?

- Do they have difficulties in retaining and applying knowledge?

The use of computer technology or a teaching software for the smooth running of the learning process during practical training or seminar makes it easier for the lecturer to observe the student's understanding of the issue and to give individual feedback - formative assessment. Timely feedback will help the student to understand the issue correctly, increase motivation and build solid knowledge. Such software are Google Classroom, Microsoft Tims, Zoom and others; their use will allow the lecturer to have at the center of the learning process the student, his/her development process and the results achieved by him/her.

Conclusions. The lecturer has the freedom to choice. in order to create a learning environment and to lead the teaching process in a differentiated way, to select a suitable and convenient for the teaching process teaching software from among those developed based on web technologies, increasing students' motivation and teaching-learning process efficiency.

\section{REFERENCES}

1. How to measure students' innovation competences in higher education: Evaluation of an assessment tool in authentic learning environments. Jani Ursin, Kari Nissinen, (2018);

2. Assessment Tools for HE Learning Environments. Supporting projects and activities in the fields of education (2017-2020);

3. Embedded Formative Assessment: (Strategies for Classroom Assessment That Drives Student Engagement and Learning). Solution Tree. Wiliam, D. (2017);

4. What Teachers Really Need to Know About Formative Assessment. Laura Greenstein, (2010);

5. Retrieved from http://www.oecd.org/education/ceri/34260938.pdf. 